Original article

\title{
MOLECULAR DETECTION OF CANINE PARAINFLUENZA VIRUS CIRCULATION AMONG HOME-OWNED DOGS IN SHIRAZ, IRAN
}

\author{
Y. RAHMANI ${ }^{1}$, M. ABBASZADEH HASIRI ${ }^{1} \&$ A. MOHAMMADI ${ }^{2}$ \\ ${ }^{1}$ Department of Clinical Studies; ${ }^{2}$ Department of Pathobiology, School of \\ Veterinary Medicine, Shiraz University, Shiraz, Iran
}

\begin{abstract}
Summary
Rahmani, Y., M. Abbaszadeh Hasiri \& A. Mohammadi, 2016. Molecular detection of canine parainfluenza virus circulation among home-owned dogs in Shiraz, Iran. Bulg. J. Vet. Med., 19, No 1, 40-46.

One of the major agents of infectious tracheobronchitis in dogs is canine parainfluinza virus (CPiV) which is known to cause acute-onset and highly transmissible cough. This study was aimed at determining the prevalence of CPI infection in dogs referred to the Veterinary Clinic of Shiraz University in 2013-2014. Nasal and tracheal swabs were taken from 30 apparently healthy dogs without respiratory signs and 50 sick dogs with clinical respiratory signs. Full set of characteristics including age, sex, breed, contact with other dogs, place of keeping, respiratory and general symptoms were recorded. The molecular detection of canine parainfluenza virus by semi nested reverse transcriptase PCR were performed and further confirmed by nucleotide sequencing of the last products. The results showed that the occurrence of CPiV infection in healthy dogs was $13.33 \%$ whereas it was $20 \%$ in dogs with respiratory signs. The sequencing and nucleotide blast showed no variation among determined sequences. The occurrence was higher in non-vaccinated and outdoor dogs. This study is the first attempt to detect $\mathrm{CPiV}$ infection in Fars province, Iran and the data obtained may be useful for outbreak preventions and to raise awareness of potential transmission of the disease to the small animals in the area.
\end{abstract}

Key words: canine parainfluinza virus, dog, infectious tracheobronchitis, Iran

\section{INTRODUCTION}

Canine infectious respiratory complex disease (CIRDC), previously called canine infectious tracheobronchitis (or kennel cough) is a highly contagious disease that is caused by the viral agents including canine adenoviruses, canine parainfluenza virus, canine respiratory coronavirus and the bacteria such as Bordetella bron- chiseptica, Mycoplasma spp. and Streptococcus zooepidemicus. The agents are transmitted by air from infected dogs, especially in poorly ventilated kennels, animal shelters, and veterinary hospitals (Ellis \& Krakowka, 2012; Ford, 2012).

One of the most common viruses believed to play a role in canine respiratory 
disease is canine parainfluenza virus (CPiV). The virus belongs to the family Paramyxoviridae, and is an enveloped RNA virus. The virus replicates in epithelial cells of the upper respiratory tract, and often causes no signs or mild respiratory illness. Respiratory disease may be more severe when co-infections with other pathogens such as Bordetella bronchiseptica are present. The incubation period is usually $3-10$ days and the virus is shed for up to 10 days after infection (Ford, 2012; Sykes, 2014).

Tissue culture inoculation (viral isolation) is not commonly performed. Polymerase chain reaction techniques to detect viruses from dogs with acute respiratory disease have been most useful for identification of pathogens. Suitable specimens for respiratory virus isolation or detection are nasal and pharyngeal swab specimens (Ford, 2012; Sykes, 2014).

In Iran, there has been no molecular research for detection of prevalence of the parainfluenza virus in dogs. Therefore, the objective of the study reported here was to determine the prevalence of parainfluenza virus infections in dogs with and without respiratory signs referred to the Veterinary Teaching Clinic at Shiraz University and evaluation of infection with some epidemiological characteristics.

\section{MATERIALS AND METHODS}

\section{Study subjects}

Nasal and tracheal swabs were obtained from 50 dogs with clinical respiratory signs (sneezing and/or coughing and/or nasal and ocular discharge) (group A) and 30 healthy dogs (group B) in the Veterinary Clinic of Shiraz University in 2013 and 2014. The swabswere kept in $10 \mathrm{~mL}$ microtubes at $-70{ }^{\circ} \mathrm{C}$. The full set of characteristics including age, sex, breed, con- tact with other dogs, place of keeping (outdoor or indoor), respiratory and general symptoms was recorded.

\section{$R N A$ extraction protocol}

Initially the swabs were soaked in $300 \mu \mathrm{L}$ of sterile PBS and $200 \mu \mathrm{l}$ of this was subjected to RNA isolation using Cinnagen RNA extraction kit (CinnaGen Co., Iran) according to the manufacturer instruction. Briefly, $1 \mathrm{~mL}$ of RNX solution was used as the lysis buffer and $200 \mu \mathrm{L}$ of chloroform was added. The aqueous phase resulted from centrifugation was transferred to a new tube and RNA was precipitated with equal volume of isopropanol. After washing two times, total RNA was eluted in $50 \mu \mathrm{L}$ of DNase/ RNase free water.

\section{PCR protocol}

The Complementary DNAs were synthesised using AccuPower ${ }^{\mathrm{R}}$ RT Premix, Bioneer, Korea. Briefly, $5 \mu \mathrm{L}$ of RNA, 10 pmol of forward primer (Table 1) and $14 \mu \mathrm{L}$ of DEPC water were transferred to the kit test tube, and then incubated at $42{ }^{\circ} \mathrm{C}$ for $1 \mathrm{~h}$ and $95^{\circ} \mathrm{C}$ for 5 minutes. Semi nested PCR was performed in a total volume of $25 \mu \mathrm{L}$ containing PCR buffer, $\mathrm{MgCl}_{2}$ (1.5 mM), dNTPs mix $(0.1 \mathrm{mM})$, the forward primer CPiV-F363 (20 pmol) for the first round (Table 1) and another forward primer CPiV-F428 (20 pmol) for the second step, the reverse primer CPiV-538 (20 pmol), taq DNA polymerase (1 U) and Complementary DNA $(5 \mu \mathrm{L})$. The programme in MJ Biorad thermo cycler was $94{ }^{\circ} \mathrm{C}$ for $3 \mathrm{~min}$ and 35 cycles of $94{ }^{\circ} \mathrm{C}$ for $30 \mathrm{~s}, 55{ }^{\circ} \mathrm{C}$ for $30 \mathrm{~s}$ and $72{ }^{\circ} \mathrm{C}$ for $30 \mathrm{~s}$. The final extension was conducted at $72{ }^{\circ} \mathrm{C}$ for $7 \mathrm{~min}$. The products were visualised after doing electrophoresis at $100 \mathrm{~V}$ in $1 \%$ agarose. The CPI vaccine was utilised as positive control and the complementary DNA synthesised from RNA of 
Molecular detection of canine parainfluenza virus circulation among home-owned dogs in Shiraz, Iran

Table 1. Oligonucleotide sequences used in semi nested RT-PCR for detecting NP gene of canine parainfluenza virus

\begin{tabular}{cccc}
\hline Primer name & Sequences & Position & Product size (bp) \\
\hline CPiV-F363 & GGGTAGAGATCGATGGCTTTGA & $363-386$ & 251 \\
CPiV-F428 & GCCGTGGAGAGATCAATGCCTAT & $428-451$ & 188 \\
CPiV-R538 & GCGCAGTCATGCACTTGCAAGT & $614-593$ & \\
\hline
\end{tabular}

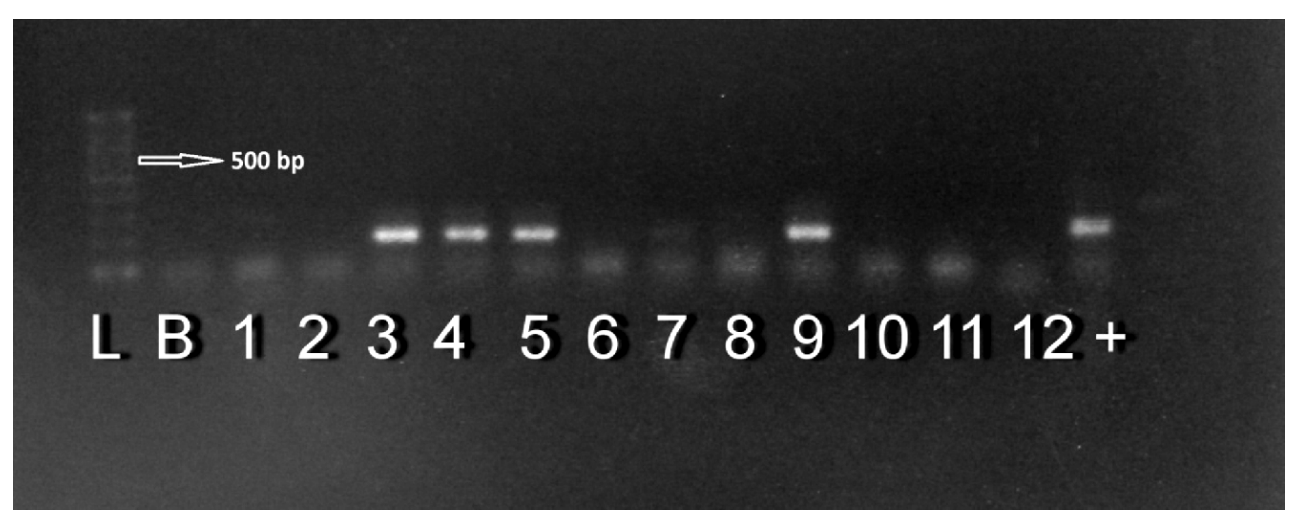

Fig. 1. The final product of the semi nested RT-PCR assay amplifying 188-bp segment of NP gene of canine parainfluenza virus. L: DNA marker (100bp), B: blank; Lanes 1, 2, 6, 7, 8, 10, 11, 12 : negative samples, Lanes 3, 4, 5 and 9: positive samples, +: positive control

(canine parainfluenza vaccine RNA).

\section{TGCCGTGGAGAGATCAATGCCTATGCTGCACTTGCAGAAGATCTACCTGACACACTA AACCATGCAACACCTTTCGTTGATTCCGAAGTCGAGGGAAC TGC ATGGGATGAGAT TGAGACTTTCTTAGATATGTGTTACAGTGTCCTAATGC AGGCATGGATAGTGACTTG CAAGTGCATGACTGCGCA}

Fig. 2. The partial nucleotide sequence of NP gene of canine parainfluenza virus.

pharyngeal epithelium of a healthy dog as a negative control.

Seven final PCR products were sequenced and analysed with blast programme of NCBI gene bank.

\section{Statistical analysis}

The relationship between infection and some risk factors was statistically analysed with Fisher test and the $\mathrm{P}$ values calculated.

\section{RESULTS}

The PCR products and nucleotide sequence of the last PCR product (188 bp) are shown in Fig. $1 \& 2$ respectively. The sequence was fully equal to partial sequence of canine parainfluenza virus nucleocapsid (N) gene (EF543648.1), canine parainfluenza virus strain FC nucleocapsid (N) gene (EF546391.1), parainfluenza virus 5 strain W3A (JQ743318.1), parainfluenza virus 5 strain CPI+ (JQ743321.1) 
Table 2. Parainfluenza infection results in dogs with respiratory signs (Group A) by PCR test

\begin{tabular}{lcc}
\hline Signalment data & $\begin{array}{c}\text { CpiV-positive dogs number } \\
(\%)\end{array}$ & $\begin{array}{c}\text { CpiV-negative dogs } \\
\text { number }(\%)\end{array}$ \\
\hline $\begin{array}{l}\text { Sex }(P=1.00) \\
\text { male }(\mathrm{n}=28)\end{array}$ & $6 / 28(21.4 \%)$ & $22 / 28(78.6 \%)$ \\
female $(\mathrm{n}=22)$ & $4 / 22(18.18 \%)$ & $18 / 22(81.82 \%)$ \\
\hline Keeping status $(P=0.03)$ & & \\
indoor $(\mathrm{n}=26)$ & $2 / 26(7.69 \%)$ & $24 / 26(92.31 \%)$ \\
outdoor $(\mathrm{n}=24)$ & $8 / 24(33.33 \%)$ & $16 / 24(66.67 \%)$ \\
\hline Presence of other dogs $(P=0.00)$ & & $5 / 13(38.47 \%)$ \\
yes $(\mathrm{n}=13)$ & $8 / 13(61.53 \%)$ & $35 / 37(94.29 \%)$ \\
no $(\mathrm{n}=37)$ & $2 / 37(5.71 \%)$ & $26 / 28(92.86 \%)$ \\
\hline Vaccination $(P=0.01)$ & & $14 / 22(63.64 \%)$ \\
complete $(\mathrm{n}=28)$ & $2 / 28(7.14 \%)$ & \\
incomplete $(\mathrm{n}=22)$ & $8 / 22(36.36 \%)$ & $21 / 27(77.78 \%)$ \\
\hline Age $(P=0.74)$ & & $19 / 23(82.61 \%)$ \\
$<1$ year $(\mathrm{n}=27)$ & $6 / 27(22.22 \%)$ & \\
$>1$ year $(\mathrm{n}=23)$ & $4 / 23(17.39 \%)$ & \\
\hline
\end{tabular}

Table 3. Parainfluenza infection results in healthy dogs (Group B) by PCR test

\begin{tabular}{|c|c|c|}
\hline Signalment data & $\begin{array}{c}\text { CpiV-positive dogs number } \\
(\%)\end{array}$ & $\begin{array}{l}\text { CpiV-negative dogs } \\
\text { number }(\%)\end{array}$ \\
\hline \multicolumn{3}{|l|}{$\operatorname{Sex}(P=1.00)$} \\
\hline $\begin{array}{l}\text { male }(n=12) \\
\text { female }(n=18)\end{array}$ & $\begin{array}{l}2 / 12(16.66 \%) \\
2 / 18(11.11 \%)\end{array}$ & $\begin{array}{l}10 / 12(83.34 \%) \\
16 / 18(88.89 \%)\end{array}$ \\
\hline \multicolumn{3}{|c|}{ Keeping status $(P=0.03)$} \\
\hline $\begin{array}{l}\text { indoor }(n=17) \\
\text { outdoor }(n=13)\end{array}$ & $\begin{array}{l}0 / 17(0 \%) \\
4 / 13(30.77 \%)\end{array}$ & $\begin{array}{l}17 / 17(100 \%) \\
9 / 13(69.23 \%)\end{array}$ \\
\hline \multicolumn{3}{|c|}{ Presence of other dogs $(P=0.03)$} \\
\hline $\begin{array}{l}\text { yes }(n=7) \\
\text { no }(n=23)\end{array}$ & $\begin{array}{ll}3 / 7 & (42.86 \%) \\
1 / 23(4.35 \%) \\
\end{array}$ & $\begin{array}{cc}4 / 7 & (57.14 \%) \\
22 / 23(95.65 \%) \\
\end{array}$ \\
\hline $\begin{array}{l}\text { Vaccination }(P=0 \\
\text { complete }(n=25) \\
\text { incomplete }(n=5)\end{array}$ & $\begin{array}{l}0 / 25(0 \%) \\
4 / 5 \quad(80 \%)\end{array}$ & $\begin{array}{c}25 / 25(100 \%) \\
1 / 5 \quad(20 \%)\end{array}$ \\
\hline \multicolumn{3}{|l|}{$\operatorname{Age}(P=0.04)$} \\
\hline $\begin{array}{l}<1 \text { year }(n=14) \\
>1 \text { year }(n=16)\end{array}$ & $\begin{array}{l}4 / 14(28.5 \%) \\
0 / 16(0 \%)\end{array}$ & $\begin{array}{l}10 / 14(71.5 \%) \\
16 / 16(100 \%)\end{array}$ \\
\hline
\end{tabular}

and parainfluenza virus 5 strain CPI(JQ743320.1).
The prevalence of parainfluenza virus infection in dogs with (group A) and 
without (group B) respiratory signs referred to the Veterinary Teaching Clinic at Shiraz university and correlation between the infection and some epidemiological characteristics have been shown in Tables 2 and 3 . The results showed that the occurrence of $\mathrm{CPiV}$ infection in healthy dogs was $13.33 \%(4 / 30)$ and $20 \%(10 / 50)$ in dogs with respiratory signs. No significant differences were seen in comparison (by Chi square test) between the total prevalence of $\mathrm{CPiV}$ in the two populations (13.3 vs 20\%) $(\mathrm{P}=0.44)$.

Although there was no significant correlation between sex and $\mathrm{CPiV}$ infection but vaccination, keeping status (indoor or outdoor) and relationship with other dogs had significant correlation with the infection in the animals of both groups. In addition, a statistical relation was found between age and infection in the animals of group B.

\section{DISCUSSION}

Although infection and disease associated with CPiV have long been recognised as an important cause of canine ITB and have been most prevalent in situations where multiple-source dogs are crowded, there has been no molecular research on the prevalence and epidemiological data in Fars province, Iran. In the present study, for the first time in Iran, molecular research was performed for detection and prevalence of the parainfluenza virus in dogs. Knowledge of the prevalence of $\mathrm{CPiV}$ in dogs in the Shiraz area is important, because this infection is highly contagious and there are many stray and rural dogs that are not vaccinated. These animals are of concern with regard to transmission of disease to other dogs (Ford, 2012). The reported results confirm that prevalence of $\mathrm{CPiV}$ infection in dogs is different, not only between countries but also between different areas of each country (Ford, 2012).

Present study indicated that this virus is present in the ecosystem. Besides, the occurrence of $\mathrm{CPiV}$ infection was found in $17.5 \%(14 / 80)$ of dogs tested, $13.33 \%$ in healthy dogs and $20 \%$ in dogs with respiratory signs. Erles et al. (2004) investigated viruses associated with canine infectious respiratory disease in England by PCR and found that $19.4 \%$ of tracheal and $10.4 \%$ of lung samples were positive for CPiV. Mochizuki et al. (2008) found $\mathrm{CPiV}$ in $7.4 \%$ of 68 household dogs showing clinical signs of respiratory infection and it was the most common etiologic agent of canine ITB in Japan. In a seroepidemiological survey of 302 healthy pet dogs in Sweden in 2003, CPiV had a seroprevalence of $28 \%$. The dogs' ages, gender or breed did not correlate with the seroprevalence (Engelund et al., 2003). In Mexico in 2004, CPiV was identified in 28 of $35(51 \%)$ cases of dogs that died from acute or subacute pneumonia (Damián et al., 2005). In another survey, a fourfold or greater rise in the titre of antibodies against canine parainfluenza virus in 79 percent of the cases revealed the etiological importance of this virus in an outbreak in Norway (Ueland, 1990). Mosallanejad et al. (2009) found that the prevalence of canine parainfluenza virus antigens is $5.3 \%$ (4 of 76 ) by means of immunochromatography in Ahvaz city, Iran. Like the present study, no significant difference was found between different sexes. Besides, in the mentioned researches a more significant prevalence was observed in dogs that were in open environment compared with closed environment (Mosallanejad et al., 2009). In the present research, outdoor dogs showed significantly more positive samples (in 
both groups) in comparison to indoor dogs $(\mathrm{P}<0.03)$. Furthermore, keeping a $\operatorname{dog}$ with other $\operatorname{dog}(\mathrm{s})$ is likely to pose a significant risk for increased infection. Similarly, in many researches, the crowding of dogs together has been significantly associated with the seroprevalence of $\mathrm{CPiV}$ and affected dogs have been more likely to have a history of recent stays in a pet shop, boarding facility, kennel or shelters (Englund et al., 2003, Sykes, 2014). The present study emphasises that the prevalence of $\mathrm{CPiV}$ is higher in kennel or open populations $(\mathrm{P}<0.03)$. The virus is highly contagious and efficiently transmitted from infected dogs through oronasal contact with aerosolised respiratory secretions. Among dogs housed in high density populations, transmission most likely occurs after direct contact with infected dogs or contact with aerosolised microdroplets, either from infected dogs or through freshly contaminated dishware, human hands, and other fomites (Ford, 2012; Sykes, 2014).

Although some research found no relation between age and infection (Mosallanejad et al., 2009), it is reported that young puppies less than 6 months of age are at increased risk (Ford, 2012). In our study, more positive samples were detected in young dogs (under 1 year old) compared to other dogs ( $>1$ year old) (significantly in group $\mathrm{B}, \mathrm{P}<0.04$ ). It could be attributed to susceptibility of young dogs to infectious viruses because of no previous contact and immature immune system.

Similar to this study, Erles et al. (2004) detected CPiV RNA in tracheal samples from dogs with all grades of CIRD as well as in samples from dogs without clinical symptoms and there was no association between the presence of CPIV and the severity of respiratory symptoms. In present study no significant differences were seen between the total prevalence of $\mathrm{CPiV}$ in the two populations (respiratory signs and no signs). There is a possibility that apparently healthy dog had an early stage of CIRD at which clinical signs would not yet have been manifested. Besides, the presence of other infectious respiratory agents (viruses or bacteria) could contribute to severity of disease and their detection was not included in this research.

The present results indicated that the infection was significantly more common in the dogs without history of vaccination $(\mathrm{P}<0.01)$. Therefore we propose proper vaccination for the protection of dogs against respiratory signs of infection with CPiV. Two of the vaccinated dogs $(7.14 \%)$ in group A were detected as infected. Due to low risk of mutation of $\mathrm{CPiV}$ and sequencing data of detected virus (from positive dogs), with appropriate cold chain of vaccines, it seems that immunity derived from vaccination might not confer complete protection against infection. It has been proven that despite the implementation of vaccination programs against the principal pathogens associated with CIRD, outbreaks continue to be reported throughout the world (Ford, 2012; Sykes, 2014). Parenteral and intranasal vaccines exist for CPiV. Although few studies have compared the efficacy of parenteral and intranasal vaccines, intranasal vaccination creates a more effective and more rapid (protects within 72 hours) protection than parenterally administered vaccines (Kontor et al., 1981). Use of intranasal $\mathrm{CPiV}$ vaccines, as opposed to parenteral vaccines, has been suggested because they produce local immunity, reduce shedding, and can be used in puppies as young as 3 to 4 weeks of age (Welborn et al., 2011). Unfortunately, the 
intranasal vaccine is not available in Iran. It seems logical for this vaccine to be provided and used in dogs, especially before keeping them with other dogs (like in kennels).

In conclusion, the results of this study indicate that $\mathrm{CPiV}$ is a common disease in dogs of Shiraz, and young, unvaccinated outdoor dogs or dogs that are kept with other dogs are at greater risk for infection. Further studies are required to fully control CPiV transmission and prevalence.

\section{REFERENCES}

Damian, M., E. Morales, G. Salas \& F. J. Trigo, 2005. Immunohistochemical detection of antigens of distemper, adenovirus and parainfluenza viruses in domestic dogs with pneumonia. Journal of Comparative Pathology, 133, 289-293.

Ellis, J. A. \& G. S. Krakowka, 2012. A review of canine parainfluenza virus infection in dogs. Journal of the American Veterinary Medical Association, 240, 273-284.

Englund, L., A. A. Jacobs, B. Klingeborn \& M. Chriél, 2003. Seroepidemiological survey of Bordetella bronchiseptica and canine parainfluenza-2 virus in dogs in Sweden. The Veterinary Record, 152, 251254.

Erles, K., E .J. Dubovi, H. W. Brooks \& J. Brownlie, 2004. Longitudinal study of viruses associated with canine infectious respiratory disease. Journal of Clinical Microbiology, 42, 4524-4529.

Ford, R. B., 2012. Canine infectious tracheobronchitis. In: Infectious Diseases of the Dog and Cat, $4^{\text {th }}$ edn, ed C. E. Green, W. B. Saunders Co., pp. 55-65.

Kontor, E. J., R. J. Wegrzyn \& R. A. Goodnow, 1981. Canine infectious tracheobronchitis: Effects of an intranasal live canine parainfluenza - Bordetella bronchiseptica vaccine on viral shedding and clinical tracheobronchitis (kennel cough).
American Journal of Veterinary Research, 42, 1694-1698.

Mochizuki, M., A. Yachi, T. Ohshima, A. Ohuchi \& T. Ishida, 2008. Etiologic study of upper respiratory infections in household dogs. Journal of Veterinary Medical Science, 70, 563-569.

Mosallanejad, B., R. Avizeh, M. R. Seyfiabad Shapouri \& B. Ramesh, 2009. Antigenic detection of Canine Parainfluenza virus in urban dogs with respiratory disease in Ahvaz area, southwestern Iran. Archives of Razi Institute, 64, 115-120.

Sykes, J. E., 2014. Canine viral respiratory infections. In: Canine and Feline Infectious Diseases, $1^{\text {st }}$ edn, Elsevier, pp. 170 178.

Ueland, K., 1990. Serological, bacteriological and clinical observations on an outbreak of canine infectious tracheobronchitis in Norway. The Veterinary Record, 126, 481483.

Welborn, L. V., J. G. DeVries, R. Ford, R. T. Franklin, K. F. Hurley, K. D. McClure, M. A. Paul \& R. D. Schultz, 2011. AAHA canine vaccination guidelines. Journal of the American Animal Hospital Association, 47, 1-42.

Paper received 25.03.2015; accepted for publication 08.05.2015

\section{Correspondence:}

M. Abbaszadeh Hasiri

Asst. Prof. of Small Animal Internal Medicine, Department of Clinical Studies, School of Veterinary Medicine, Shiraz University, P.O. Box 1731, 71345, Shiraz, Iran tel: +98 $7132288660,+989177070881$, fax: +987132286950 e-mail: abbaszadeh@shirazu.ac.ir 